\title{
Ciência, aUtoria e verdade nos ditos do MOVIMENTO ESCOLA SEM PARTIDO: O MECANISMO DA DENÚNCIA
}

\author{
Elvis Patrik KATZ* \\ Andresa Silva da Costa MUTZ**
}

\begin{abstract}
RESUMO: O movimento Escola Sem Partido vem, desde o início dos anos 2000, se notabilizando no Brasil por lançar sucessivas investidas de poder sobre a categoria docente. Para tal empreendimento, foi necessário, entre outras ações, fabricar um conjunto de saberes que lhe conferisse certa legitimidade no campo da Educação. Analisamos, neste artigo, a partir do referencial teórico proveniente dos Estudos Culturais e sob inspiração do pensamento de Michel Foucault, aquilo que denominamos como mecanismo da denúncia: estratégia estabelecida a fim de representar o movimento como verdadeiro e necessário ao nosso tempo. $\mathrm{O}$ material empírico selecionado para esta pesquisa esteve composto por 127 artigos retirados do sítio escolasempartido.org. A investigação permitiu verificar o modo como o Escola Sem Partido opera na construção do discurso que aponta para uma suposta hegemonia da doutrinação ideológica nas escolas, envolvendo-se numa disputa pela verdade em um processo no qual rivalizava, inclusive, com a própria literatura acadêmica educacional.
\end{abstract}

PALAVRAS-CHAVE: Escola Sem Partido. Denúncia. Verdade. Poder. Ciência.

\footnotetext{
* FURG - Universidade Federal do Rio Grande. PPGEDU - Programa de Pós-Graduação em Educação. Rio Grande - RS - Brasil. 96203-900 - elviskatz@yahoo.com.br. https://orcid.org/0000-0001-6050-214X.

** UFRGS - Universidade Federal do Rio Grande do Sul - Departamento Interdisciplinar Campus Litoral Norte - Emboabas - RS - Brasil. 95590-000 - andresa.mutz@ufrgs.br. https://orcid.org/0000-0002-6869370X.
} 
Introdução

$\mathrm{O}$ artigo que ora apresentamos decorre de uma pesquisa de mestrado realizada no sul do Brasil ${ }^{59}$. Constitui-se em um fragmento dos resultados coletados de uma investigação ao longo de dois anos de trabalho, estando sustentado sobre um corpus documental de mais de 127 artigos retirados do sítio digital escolasempartido.org. Amparados pelas ferramentas teóricas da vertente foucaultiana dos Estudos Culturais, procuramos verificar o modo como o movimento Escola Sem Partido (ESP) ${ }^{60}$ põe em circulação e naturaliza, desde sua fundação, a ideia de que os estudantes brasileiros estariam sofrendo doutrinação ideológica. Portanto, para o movimento, a vigilância por parte da sociedade civil e do Estado é importante para regrar o comportamento dos professores, ajustando suas identidades conforme modelos desejáveis de conduta igualmente idealizados pelo movimento.

Procedimentalmente, as etapas envolvidas na construção dos dados para este recorte envolveram: 1) a identificação dos autores selecionados pelo ESP para garantir certa solidez às suas proposições junto à população de um modo geral; 2) a verificação da maneira como o ESP aproxima tais proposições com a Ciência e a verdade, também com intuito de afastar críticas relacionadas - principalmente - aos professores e especialistas da Educação. Os resultados nos permitiram identificar a constituição, por parte do movimento, daquilo que denominamos como mecanismo da denúncia, sobretudo no que se refere ao modo como esse instrumento de poder é utilizado pelo ESP para tornar suas ações justificáveis e sua existência necessária. Dito de outra forma, por meio da estratégia da denúncia (além da evidente tentativa de controle da conduta dos professores), pudemos perceber como os integrantes do movimento buscam legitimar certos enunciados como verdadeiros, apelando para a voz de intelectuais e para a natureza científica da educação.

Nesse sentido, na primeira seção, o artigo apresenta uma definição da noção de mecanismo (conforme ensaiada por Michel Foucault) com intuito de introduzir a discussão acerca do modo como ele opera na construção da ideia de uma suposta doutrinação ideológica de esquerda no Brasil. Na segunda seção, nos debruçamos sobre os achados da pesquisa, analisando os autores mais frequentemente utilizados pelo ESP e as formas pelas quais o movimento intenta adquirir legitimidade na

59 Dissertação de Mestrado defendida junto ao Programa de Pós-Graduação em Educação da Universidade Federal do Rio Grande (FURG), financiada parcialmente pela Coordenação de Aperfeiçoamento de Pessoal de Nível Superior (CAPES).

$60 \mathrm{Em}$ alguns momentos, optou-se pela sigla ESP no lugar de Escola Sem Partido, com objetivo de tornar a leitura mais rápida e agradável. 
construção de enunciados que se autoidentificam como mais verdadeiros, pois são científicos.

\section{O mecanismo como estratégia}

Uma leitura foucaultiana da estratégia de poder utilizada pelo Escola Sem Partido nos permitiu enxergar como os ataques à identidade docente se dão em diferentes frentes de batalha. Isso quer dizer que as investidas de poder podem se desmembrar em ações variadas que envolvem não apenas a produção de saberes correlatos a essas investidas, mas também um mecanismo que coloque saberes e técnicas em funcionamento com objetivos específicos de governar a conduta docente.

Dessa forma, pretendemos aqui descrever o que entendemos por mecanismo da denúncia. Assim como outros conceitos presentes na obra de Michel Foucault, a ideia de mecanismo deve ser vista sempre localizada em um contexto particular. Por isso, escolhemos explicar em que consiste um mecanismo através da descrição feita pelo filósofo francês em Vigiar e Punir, quando ele discorre acerca do mecanismo do exame:

O exame combina as técnicas da hierarquia que vigia e as da sanção que normaliza. É um controle normalizante, uma vigilância que permite qualificar, classificar e punir. Estabelece sobre os indivíduos uma visibilidade através da qual eles são diferenciados e sancionados. É por isso que, em todos os dispositivos de disciplina, o exame é altamente ritualizado [...]. Pois, nessa técnica delicada estão comprometidos todo um campo de saber, todo um tipo de poder. [...] Mas sua própria tecnologia, esse pequeno esquema operatório que tem tal difusão (da psiquiatria à pedagogia, do diagnóstico das doenças à contratação de mão de obra), esse processo tão familiar do exame, não põe em funcionamento, dentro de um só mecanismo, relações de poder que permitem obter e constituir saber? $O$ investimento político não se faz simplesmente ao nível da consciência, das representações e no que julgamos saber, mas ao nível daquilo que toma possível algum saber (FOUCAULT, 2010, p.154, Grifo nosso). 
Sendo assim, o mecanismo é entendido, no pensamento foucaultiano, como uma ferramenta de produção de saberes em função das demandas de poder de uma estratégia. No caso do exame, por exemplo, tal estratégia está submetida ao tipo de poder disciplinar.

O que denominamos mecanismo da denúncia, no caso do ESP, atende aos anseios das investidas de poder como forma de conduzir as condutas dos professores. Estas, conforme Katz e Mutz (2018), têm caráter de provocação permanente sobre as identidades docentes, buscando a produção de subjetividades a partir do uso de técnicas de poder educativas, políticas e jurídicas.

Por outro lado, como foco de interesse deste artigo, o mecanismo também coloca em funcionamento técnicas de poder que se servem de e produzem outros saberes, construindo uma relação recíproca entre técnicas e mecanismo para governar os sujeitos. Os mecanismos são como instrumentos que podem ser transportados de um dispositivo a outro, de um tipo de poder para outro, mesmo que sirvam a necessidades diferentes. Assim como o exame é um mecanismo da estratégia disciplinar que coloca técnicas em movimento e produz saberes úteis a essas práticas, a denúncia é o mecanismo da estratégia do Escola Sem Partido para colocar em ação técnicas educativo-políticas e jurídicas e, paralelamente, produzir saberes úteis a justificação das condutas da organização.

Chama igualmente a atenção a forma de apresentação das "denúncias" colhidas por esse meio, já que relatos escritos, extratos de postagens pessoais em redes sociais, gravações e filmagens de trechos de aulas são divulgados na página de abertura do site, expondo publicamente as pessoas (inclusive alunos) sem qualquer mediação. Cabe observar, a esse respeito, a dupla instrumentalidade dessa forma de exposição que, a título de defender direitos, reúne elementos que legitimam e autorizam a posição acusatória do Escola sem Partido, conferindo-lhe confiabilidade (especialmente nas esferas conservadoras, claro!), sobrepondo-o aos espaços e regras institucionais no âmbito dos quais as questões escolares deveriam ser tratadas, bem como intimidando e constrangendo profissionais e alunos no âmbito escolar, ao propagar a ameaça da disseminação de práticas de registro clandestino e de divulgação pública das suas atividades e diálogos (ALGEBAILE, 2017, p.68-69). 
Assim, a denúncia tem função essencial dentro da estratégia escolhida pelo ESP por alguns motivos: a) em última análise, ela funciona como garantia de todas as proposições feitas pelo movimento; b) da mesma forma, fornece o material da crítica à doutrinação ideológica nas escolas. Assim, a denúncia funciona como uma maneira de fabricar as realidades que o Escola Sem Partido critica, mas também justifica, dentro de sua lógica própria, a necessidade da existência das propostas defendidas pela organização. Isso significa que a denúncia é produtora de saberes e criadora da condição de existência da qual o movimento se vale; poder-se-ia dizer que, sem esse mecanismo, o ESP não conseguiria sustentar seus argumentos de maneira eficaz.

O mecanismo da denúncia, no caso do ESP, opera através da naturalização de uma realidade específica - a suposta doutrinação ideológica - que sirva necessariamente a seus fins políticos de resistência ao avanço da esquerda no âmbito das instituições escolares. $\mathrm{O}$ incentivo à denúncia - o site do movimento fornece um passo a passo aos estudantes, disponibilizando modelos de petições judiciais e tutorial para gravação de uma aula, por exemplo - oferece ao Escola Sem Partido não apenas um material que justifique suas demandas contrárias ao que ele chama de hegemonia da doutrinação ideológica, mas recomendações que intentam alcançar a lisura do processo denuncista que asseguraria a proteção do próprio movimento, evitando publicar acusações pouco confiáveis ou mentirosas. O compromisso com certo grau de veracidade, assim, indica que o movimento se insere na disputa pelo verdadeiro, e é por esse ângulo que a denúncia é tão importante. Tal mecanismo oferece saberes que tornam verificáveis as afirmações da organização, de modo que ela possa advogar suas causas com o mínimo de fundamentação necessária para convencer ou, na pior das hipóteses, ameaçar os professores tidos como doutrinadores.

Com raciocínio circular, o ESP justifica sua existência pela necessidade de combate a uma situação de doutrinação generalizada que supostamente ocorreria na escola. Tendo em vista que não há como comprovar a existência dessa doutrinação de forma concreta (a não ser, é claro, pelos depoimentos que o próprio movimento estimula, gerencia e publica em seu site), o ESP argumenta que a inexistência de ações contra a doutrinação seria justamente o sintoma mais evidente de que a tal doutrinação é mesmo muito produtiva. Ou seja, segundo a organização, se não há provas da hegemonia de doutrinação é porque ela mascarou tão bem os fatos, enganou tão competentemente os estudantes e, por fim, conquistou tão habilmente as instituições de ensino responsáveis pela produção do conhecimento, que não se faz mais notar. Sintetizando, a ausência de provas corroboraria a existência do problema da doutrinação. 


\section{Autorizando ditos: usos da Ciência e vozes intelectuais}

Esta pesquisa nos permitiu demarcar pelo menos dois aspectos que tornam significativo o mecanismo denuncista do ESP, permitindo-nos identificá-los como estratégias de condução das condutas dos sujeitos: 1) $O$ fato de lançar mão de especialistas que estariam autorizados - como se os professores não o estivessem - a analisar o caso da suposta doutrinação ideológica; 2) o apelo aos métodos que tornam um conhecimento objetivo (conforme o modelo de veridicção inaugurado na Modernidade) como modo de opor a Ciência aos subjetivos abusos da liberdade de ensinar praticados pelos professores.

Segundo Foucault (1979), a constituição de práticas e de técnicas que visem o governo dos sujeitos implica a conquista do campo do verdadeiro. Basicamente, isso manifesta duas coisas: num sentido, que o exercício do poder demanda sempre certa produção de saberes que tornem possíveis as ações pretendidas; em outro sentido, que o próprio exercício do poder constrói - ele mesmo - outros saberes. No entanto, eles só podem ser considerados válidos ao serem legitimados enquanto conhecimentos, saberes verdadeiros.

O importante, creio, é que a verdade não existe fora do poder ou sem poder [...] A verdade é deste mundo; ela é produzida nele graças a múltiplas coerções e nele produz efeitos regulamentados de poder. Cada sociedade tem seu regime de verdade, sua "política geral" de verdade: isto é, os tipos de discurso que ela acolhe e faz funcionar como verdadeiros; os mecanismos e as instâncias que permitem distinguir os enunciados verdadeiros dos falsos, a maneira como se sanciona uns e outros; as técnicas e os procedimentos que são valorizados para a obtenção da verdade; o estatuto daqueles que têm o encargo de dizer o que funciona como verdadeiro. (FOUCAULT, 1979, p.13, Grifo nosso).

Isso não ocorre sem motivo: em uma época na qual a vontade de verdade impera e a Ciência procura elucidar todos os fenômenos da realidade, o Escola Sem Partido precisa, mesmo que minimamente, respeitar os rituais da ciência pedagógica. Ele sente-se coagido, enfim, a pronunciar não apenas discursos inspirados nas regras do conhecimento científico, mas explicar-se toda vez que fugir de tais normas de operação e produção do verdadeiro. 
Ora, essa vontade de verdade, como os outros sistemas de exclusão, apoia-se sobre um suporte institucional: é ao mesmo tempo reforçada e reconduzida por toda uma espessura de práticas como a pedagogia, é claro, como o sistema dos livros, da edição, das bibliotecas, como as sociedades de sábios outrora, os laboratórios hoje. Mas ela é também reconduzida, mais profundamente sem dúvida, pelo modo como o saber é aplicado em uma sociedade, como é valorizado, distribuído, repartido e de certo modo atribuído [...] Enfim, creio que essa vontade de verdade apoiada sobre um suporte e uma distribuição institucional tende a exercer sobre os outros discursos - estou sempre falando de nossa sociedade - uma espécie de pressão e como que um poder de coerção. Penso na maneira como a literatura ocidental teve de buscar apoio, durante séculos, no natural, no verossímil, na sinceridade, na ciência também - em suma, no discurso verdadeiro (FOUCAULT, 2014, p.17, Grifo nosso).

É nesse contexto de legitimação do discurso proferido pelo movimento que os artigos publicados no site escolasempartido.org utilizaram-se da expressividade de determinados pensadores e autores reconhecidos na mídia brasileira e, ao mesmo tempo, buscaram constituir um conhecimento aceitável nos termos de um discurso pedagógico verdadeiro e científico.

No entanto, há a necessidade de contemporizar tal afirmação: no Brasil, como se sabe, a pedagogia é atravessada por diferentes discursos que emergem de campos de saber distintos da Educação. Mesmo que exista um corpo de especialistas que, sobretudo na Universidade, se dedica à reflexão rigorosa e apurada do tema, muitas vezes as mídias (jornais, revistas, a Internet, a televisão, etc) - e os atores que dela fazem parte - acabam por emitir juízos sem qualquer fundamentação no campo especializado. Assim, diferentemente de outras áreas mais protegidas do saber, como Medicina, Direito e Engenharia, por exemplo, a Educação não é tratada como um local de fala exclusiva dos especialistas, mas território que é seguidamente contestado por diferentes indivíduos ou grupos: políticos, jornalistas, escritores, economistas e administradores estão entre aqueles que constantemente se referem à Educação tendo como sustentação de seus ditos apenas a sua experiência da vida escolar. É claro que as mídias não compõem toda a cultura, mas os Estudos Culturais vêm mostrando que elas têm papel cada vez mais determinante na construção das identidades culturais contemporâneas. 
O que nossa pesquisa permitiu verificar foi que o Escola Sem Partido se aproveita dessa fragilidade do discurso pedagógico brasileiro para utilizar como seus porta-vozes os mais diversos intelectuais liberais e conservadores, não necessariamente especialistas em educação. Com isso, busca constituir um conhecimento pedagógico fora da disciplina pedagógica, sendo produzido por autores sem qualquer formação na área (em sua maioria). Segundo o corpus documental, tudo isso só foi possível a partir da utilização dessas rachaduras e espaços no campo educativo brasileiro. Assim, o corpus acaba atravessado por todos esses ditos alienígenas e, de certa forma, nos termos foucaultianos, não consegue impor sua força discursiva através de sistemas eficientes de interdição e exclusão.

Para sermos mais exaustivos, poderíamos citar alguns autores que foram esses porta-vozes do Escola Sem Partido entre 2004 e 2014: Olavo de Carvalho, Onyx Lorenzoni, Nelson Lehmann da Silva, Reinaldo Azevedo, Fabio Lins, Luis Lopes Diniz Filho, Thomas Sowell, José Osvaldo de Meira Penna, Durval Lourenço Pereira Júnior, Augusto Araujo, Leandro Narloch, Carlos Alberto Sardenberg, Percival Puggina, Janaina Conceição Paschoal, Demétrio Magnoli, José Maria e Silva, Rodrigo Constantino, Luiz Felipe Pondé, Orley José da Silva, Miguel Nagib, entre outros. Nagib é o coordenador da organização e também é advogado e procurador do estado de São Paulo desde 1985, em Brasília-DF. Os demais se dividem entre escritores, jornalistas, juristas e cientistas das mais diversas áreas. Contudo, na impossibilidade de falar de cada um com a profundidade necessária, escolhemos alguns desses citados entre aqueles que tiveram mais textos utilizados no site do movimento.

Dessa forma, o primeiro autor que merece destaque é Olavo de Carvalho. Nascido em Campinas, São Paulo, Olavo Luiz Pimentel de Carvalho autodenomina-se filósofo, escritor, jornalista e conferencista. De fato, o intelectual possui registro de jornalista profissional por tempo de serviço, mas não possui nenhuma formação em nível superior reconhecida. A justificativa é, no mínimo, curiosa. Segundo seu currículo:

Desde muito jovem iniciou seus estudos de filosofia, psicologia e religiões comparadas. Não tendo encontrado, na época, cursos universitários de boa qualidade sobre os tópicos que eram de seu interesse [...] abdicou temporariamente dos estudos universitários formais e buscou professores particulares e conselheiros qualificados que o orientassem. [Eles foram] merecedores de sua mais profunda gratidão, por lhe haverem dado acesso a uma 
formação que jamais poderia adquirir numa universidade brasileira $^{61}$ (CARVALHO, 2017, Grifo nosso).

Carvalho (2017) cita intelectuais que teriam lhe orientado em seus estudos: dois filólogos, três eruditos, um esoterista, um religioso, um físico e um psicólogo. Alguns autores contemplam mais de uma categoria mencionada, mas isso é quase irrelevante diante do principal, que corrobora muito bem o que grifamos na citação última: de todos os autores, nenhum é brasileiro. Daí a justificativa da ausência de formação acadêmica dada pelo autor - a universidade brasileira e seus membros não estariam num nível razoável e, portanto, o fato de não possuir um diploma se transforma, no discurso dele, em um mérito, não sendo uma deficiência. Entretanto, é preciso sublinhar que a tentativa do autor de explicar sua posição de erudito sem um suporte institucional só reforça a potência dos discursos científicos e suas ferramentas - entre elas, a instituição universitária. "É sempre possível dizer o verdadeiro no espaço de uma exterioridade selvagem; mas não nos encontramos no verdadeiro senão obedecendo às regras de uma 'polícia' discursiva que devemos reativar em cada um de nossos discursos" (FOUCAULT, 2014, p.34). Ou seja, diante do conhecimento produzido pelo autor, a própria necessidade de justificar a ausência do estatuto institucional fez com que o Olavo de Carvalho evidenciasse ainda mais a relação estreita entre a vontade de verdade e seus aparelhos de legitimação em uma sociedade como a nossa. Mesmo querendo estar fora do mundo acadêmico e científico brasileiro, Carvalho precisou esclarecer porque isso não seria, na sua visão, um problema, o que acaba, finalmente, por reforçar a centralidade do conhecimento acadêmico institucionalizado.

A retórica usada pelo autor é muito parecida com a do próprio Escola Sem Partido. Para ele, também é preciso construir suas teses sobre algumas bases exigidas pelo discurso científico hegemônico, mesmo quando o movimento tenta se contrapor a essa situação. A força de uma vontade de verdade - para usar uma expressão de Foucault (2014) - fica cada vez mais nítida conforme se percebe que, mesmo quando se quer estar fora de um discurso científico, necessita-se explicar essa ausência e produzir saberes que possam lutar no lugar desse estatuto fornecido pelos títulos acadêmicos.

Diferentemente de Olavo de Carvalho, outros autores têm os títulos que lhes garantiriam a autoridade de serem porta-vozes do movimento. $\mathrm{O}$ fato de diversos artigos da organização mencionarem a formação acadêmica desses intelectuais

\footnotetext{
${ }^{61}$ Disponível em: <http://wpress.olavodecarvalho.org/wp-content/uploads/2017/06/Olavo-de-CarvalhoCurr\%C3\%ADculo.pdf>. Acessado em: 18. Nov. 2017.
} 
demonstra novamente como ela é valorizada pelo ESP. É o caso de Reinaldo Azevedo, formado em Jornalismo pela Universidade Metodista de São Paulo e, por muito tempo, colunista da Revista Veja. Outro exemplo é o de Rodrigo Constantino, graduado em Economia pela Pontifícia Universidade Católica do Rio de Janeiro (PUC-RJ) com Master of Business Administration (MBA) em Finanças pelo Instituto Brasileiro de Mercado de Capitais (Ibmec) do Rio de Janeiro e que também foi colunista da Veja. Ambos são expoentes da direita liberal e foram constantemente citados no site do Escola Sem Partido. O primeiro, inclusive, era o autor com mais artigos do sítio, com 17 textos publicados. Em segundo lugar, em 2014, estava Olavo de Carvalho, com 13 artigos.

Com esses dois autores, a despeito da titulação ou do respaldo acadêmico, o movimento parece querer antes de tudo aproveitar o prestígio que ambos já angariavam com certa parcela da sociedade. Mesmo que quisesse passar como indiferente ao campo especializado da educação, o ESP poderia estar tentando compensar as suas deficiências teóricas e de dados com a utilização de porta-vozes reconhecidos. O autor funcionaria, assim, como forma de contornar a pedagogia (disciplina) e o campo de pesquisas da educação (sustentado pela instituição universitária) e apareceria "como princípio de agrupamento do discurso, como unidade e origem de suas significações, como foco de sua coerência" (FOUCAULT, 2014, p.25).

Além disso, os próprios autores não são tomados como única medida para garantir a veracidade do discurso pronunciado pelo Escola Sem Partido. Como já anunciamos, também foi possível verificar um segundo aspecto relativo ao mecanismo da denúncia, estabelecido pelo movimento. Referimo-nos, aqui, ao uso de recursos científicos que permitem ao ESP tomar certos conhecimentos e revesti-los de um caráter científico, quer seja pelo uso da estatística e da matemática, por exemplo, ou ainda por meio do apelo à racionalidade em oposição à subjetividade inerente ao exercício docente.

Vejamos o caso do uso que o ESP faz de uma pesquisa realizada, segundo o movimento, pelo Instituto Sensus, vinculado a Confederação Nacional dos Transportes (CNT), a pedido da Revista Veja. 
Quadro 1 - Demonstrativo com dados da pesquisa encomendada pela Revista Veja ao Instituto

Sensus/CNT

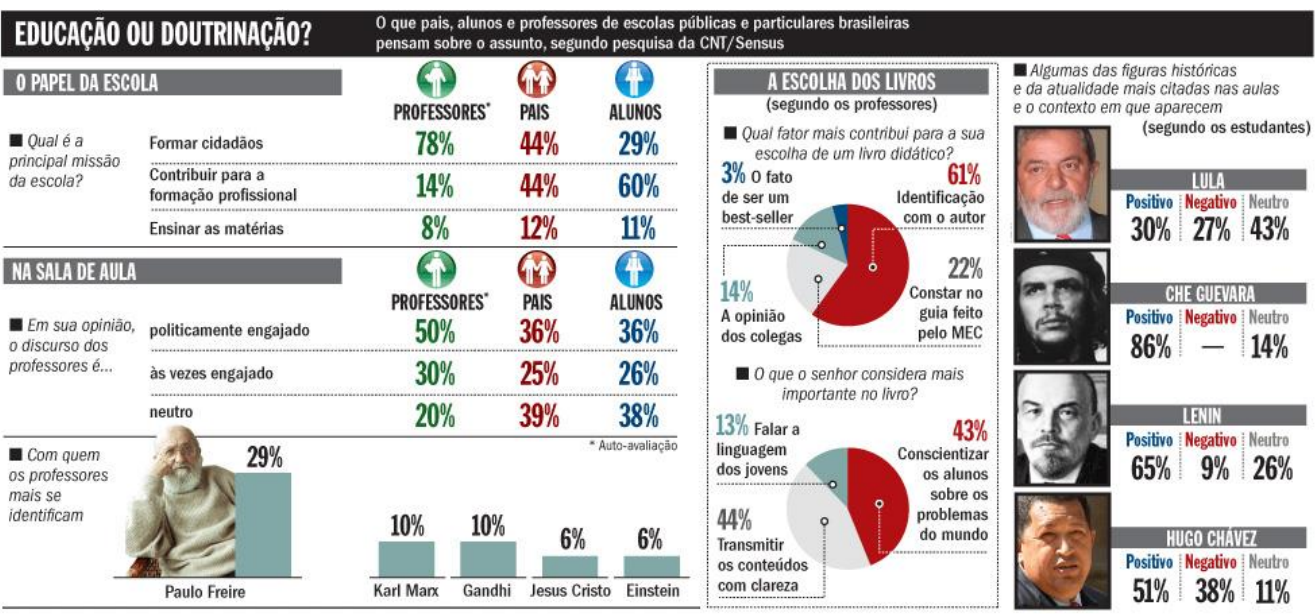

Fonte: Escola Sem Partido. Disponível em <http://www.escolasempartido.org/faq>. Acessado em: 18 Nov. 2017.

O Quadro 1 aparece em pelo menos dois artigos analisados no conjunto de materiais empíricos desta pesquisa. Nas duas descrições, no entanto, há algumas diferenças interessantes. $\mathrm{Na}$ aba $\mathrm{FAQ}^{62}$ do website original do movimento, afirma-se que, "segundo pesquisa realizada pelo Instituto Sensus [...], a imensa maioria dos professores (78\%) acredita que a principal missão da escola é 'despertar a consciência crítica dos alunos"” (ESP, IDE 004, 2016) ${ }^{63}$. Na aba FAQ do site do Escola Sem Partido, dedicada apenas à propagação dos projetos de leis do movimento, há a seguinte análise do quadro: "Segundo pesquisa realizada pelo Instituto Sensus em 2008, 80\% dos professores reconhecem que o seu discurso em sala de aula é ‘politicamente engajado' [...] Esses números corroboram a percepção de muitos alunos e ex-alunos, que se reconhecem como vítimas da doutrinação política e ideológica em sala de aula" (ESP, IDE 006, 2016).

Deixando de lado as distorções na interpretação do Quadro 1, pode-se ainda ressaltar que, apesar de não ser muito explorado, ele é utilizado pelo ESP com o objetivo de convencer a população em geral, de uma vez por todas, de que a doutrinação ideológica existe e é um problema real a ser enfrentado. Trata-se de

\footnotetext{
62 Frequently Asked Questions.

63 Todas as referências às fontes estão acompanhadas dos seus respectivos códigos de identificação no corpus documental. Há duas categorias de documentos, os quais estão discriminados por IDE (para categoria 1) CON (para categoria 2) e o número do documento (1 ao 127 na Cat. 1, e 1 ao 14 para a Cat. 2).
} 
ferramenta muito importante, tendo em vista que foi sob o argumento da existência da doutrinação e no fato de ela ser hegemônica que o Escola Sem Partido sustentou suas teses e sua função de resistência, como mencionamos anteriormente.

Ademais, é bastante revelador o modo como a imagem transmite uma mensagem (deixamos claro que não nos baseamos em nenhuma análise semiótica para fazer tal afirmação). Para representar seu conteúdo, mesmo que seus dados não sejam tão expressivos, o autor do artefato faz uma seleção de figuras marcantes da esquerda latino-americana, brasileira e mundial, uma após a outra. Evidentemente, Paulo Freire, Lênin, Lula, Che Guevara e Hugo Chávez não foram escolhidos ao acaso. As estatísticas, enquanto tecnologias de governo que têm sua história nas raízes do Estado Moderno, “[...] operam duplamente: por um lado, conduzem à tomada de decisão para intervir; por outro, pelo discurso numérico, expressam os efeitos das intervenções propostas" (TRAVERSINI; BELLO, 2009, p.145), acabando por inspirar a utilização das informações no contexto da montagem do Quadro 1.

Nesse sentido, a própria escolha das cores e disposição dos dados que o compõem é curiosa. Nos dois gráficos, por exemplo - os quais mostram o que é mais importante para um professor na hora da escolha do livro didático -, os dados que mostram a prevalência pela conscientização dos alunos para os problemas mundiais e a transmissão dos conteúdos com clareza são praticamente iguais, $43 \%$ e 44\%, respectivamente. Contudo, os $44 \%$ de valorização da transmissão do conteúdo são apresentados em tons de cinza, enquanto os $43 \%$ de professores que valorizavam a conscientização (entendida como doutrinação de esquerda) aparecem em vermelho.

Em síntese, as escolhas feitas no modo como as informações são organizadas, bem como a disposição das imagens que acompanham os números, têm por objetivo transmitir determinada mensagem, qual seja: os dados devem mostrar, naquele contexto, que o problema da doutrinação existe e, por conta disso, deve ser combatido. Nessa tarefa de conscientização sobre o problema, vale, inclusive, a interpretação parcial das informações - como a organização fez.

Poder-se-ia estender o trabalho analítico muito mais longe, percebendo não apenas dados ligados a esse quadro, mas questionando os próprios textos do movimento com o mesmo caráter crítico. Porém, esse não é o objeto central deste artigo: para os fins de descrição do mecanismo da denúncia, portanto, basta mostrar como o Quadro 1 exemplifica a tentativa de construção de um conhecimento digno de ser considerado verdadeiro. Tudo faz parte de uma estratégia de convencimento de que as teses do ESP não apenas são justas, mas necessárias.

Outro fator interessante que emergiu na análise e que também permite que o Escola Sem Partido tente se legitimar como discurso verdadeiro foi a iniciativa de 
defender a indispensabilidade de uma objetividade científica na prática pedagógica dos professores. Essa objetividade exigida pelo movimento seria uma forma de responder às acusações de que ele defenderia a neutralidade do professor, quando na realidade, segundo suas palavras, esse seria um argumento falacioso de seus opositores.

Afinal, existe neutralidade ideológica? A objetividade científica não é um mito? A justificativa-padrão utilizada pelos promotores da doutrinação ideológica nas escolas é a de que "não existe imparcialidade", já que "todo mundo tem um lado". Para os professores e autores militantes, isto resolve o problema, pois, se não existe neutralidade, cada um que cuide de "puxar a brasa para a sua sardinha”. A dose de má-fé embutida nesse raciocínio é extraordinária. $\mathrm{O}$ fato de o conhecimento ser vulnerável à distorção ideológica - o que é uma realidade inegável, sobretudo no campo das ciências sociais - deveria servir de alerta para que os educadores adotassem as precauções metodológicas necessárias para reduzir a distorção. Em vez disso, a militância utiliza esse fato como salvo conduto para a doutrinação (ESP, IDE 004, 2016).

A objetividade científica é a resposta dada pelo Escola Sem Partido na impossibilidade de exigir dos professores a neutralidade de suas práticas. Com isso, ele escapa de exigir dos docentes algo que eles não poderiam cumprir: eis a importância desse argumento. Segundo o ESP, o cientista, mesmo quando admite não poder deixar de se posicionar politicamente quanto à pesquisa, faz valer o imperativo ético de não confundir essa impossibilidade com a liberdade de propagandear e defender apenas aquilo que já acredita nos seus resultados.

Temos, então, um paralelo interessante: enquanto o pesquisador utiliza métodos reconhecidos para afastar os resultados de sua ciência da subjetividade, igualmente o professor deveria utilizar práticas pedagógicas que oportunizem o ensino livre da suposta doutrinação. Há, portanto, uma argumentação muito bem amarrada para que o professor não possa negar a dose de má fé quando decide pronunciar seus ideais em caráter de convencimento em sala de aula.

O limite da prática docente estaria determinado por uma objetividade científica inspirada naquela que o cientista tem com seu objeto: nisso, consiste a tal liberdade de ensinar - defendida pela organização. Diferente da liberdade de expressão, a liberdade de ensinar na verdade exige o cumprimento de um currículo. Portanto, o currículo obrigatório, a vontade de verdade e os procedimentos metodológicos de uma pesquisa científica deveriam ser os elementos a prevalecer 
sobre a ideologia do professor e a subjetividade do pesquisador, respectivamente. Retomando a questão da objetividade científica, observa-se o Escola Sem Partido tentar utilizar tais justificativas criadas pela ideia de objetividade científica e pela liberdade de ensinar razoável para aproximar-se da legitimação oferecida pelo discurso científico, como citado anteriormente (ESP, IDE 004, 2016).

\section{Considerações finais}

Em síntese, vale destacar que, para o Escola Sem Partido, não basta apenas criticar a doutrinação e dizer o verdadeiro num espaço selvagem, como explicamos há pouco. É preciso colar-se (mesmo que minimamente) a um campo de saber, a uma disciplina, requisitar uma legitimação dada por uma instituição universitária e, na sua ausência, no caso do ESP, se aproveitar do prestígio previamente consolidado por certo número de autores. Essa seria a etapa final do mecanismo da denúncia, iniciado com o incentivo de narrativas sobre a doutrinação, a convocação de alguns instauradores discursivos (os autores) e a construção de um conhecimento verdadeiro. Tudo isso, no fim das contas, para aproximar as enunciações do ESP dos discursos científicos reinantes de nossa época.

Dito de outro modo, vimos que o ESP busca garantir a solidez das suas proposições junto à população através da utilização de certo número de procedimentos que, de uma forma ou de outra, querem validar o que a organização propagandeia. Em geral, tais saberes desejam construir a ideia de que a educação brasileira (a escolar, sobretudo) está infestada da mais intensa doutrinação ideológica e que essa prática é realizada hegemonicamente pelos setores da esquerda política. Para angariar apoiadores e sustentar as afirmações mencionadas, o Escola Sem Partido usa da reputação de autores conhecidos na mídia nacional, apoiando-se nos textos por eles escritos para comprovar suas teses. Além disso, o movimento também se mostra como representante de uma objetividade científica a ser aplicada na educação. Quando não consegue se aproveitar do discurso científico, o ESP adota a posição antissistema, questionando a seriedade da produção acadêmica contemporânea, supostamente contaminada pelos ideais esquerdistas.

Cabe dizer, enfim, que a investigação descreveu a forma como o Escola Sem Partido opera na formação de um discurso voltado para o convencimento de que existiria uma suposta hegemonia da doutrinação ideológica nas escolas brasileiras quase sempre de esquerda. Ao fabricar essa realidade utilizando-se do mecanismo da denúncia, o ESP visou legitimar sua existência e seus ditos, sempre com vistas a 
investir sobre as identidades docentes contemporâneas. No contexto geral das investidas de poder lançadas pelo movimento, como demonstramos aqui, o mecanismo da denúncia é parte fundamental, imprescindível.

As pesquisas futuras poderiam avançar no sentido de compreender quais foram as transformações que marcaram o movimento Escola Sem Partido após 2014, quando passou a utilizar com mais intensidade as redes sociais para divulgar suas teses. Seria interessante perguntar, então, quais os efeitos dessa mudança de plataforma de divulgação? Será que ela, ao oportunizar a publicação de mais denúncias, não acabou tornando desnecessário o uso das vozes de autores consagrados pela mídia? Em que dimensão tal fenômeno se relaciona com o fato de o conservadorismo antissistema ter adquirido mais força em nossa sociedade nos últimos anos? Essas são algumas provocações aos que futuramente irão se debruçar sobre tais intentos de poder acerca da identidade docente, as quais são impossíveis de se ignorar.

\section{SCIENCE, AUTHORSHIP AND TRUTH IN STATEMENTS OF THE MOVEMENT 'ESCOLA SEM PARTIDO': THE MECHANISM OF DENOUNCEMENT}

ABSTRACT: The movement Escola Sem Partido has become known in recent years, in Brazil, for launching successive attacks of power against the teaching category. For such an undertaking, it was necessary, among other actions, to create a set of knowledges which gave them certain legitimacy in the field of Education. In this paper, we analyzed from the theoretical reference from the Cultural Studies and inspired by the ideas of Michel Foucault, what we named as the denouncement mechanism, a strategy established in order to represent the movement as true and necessary to our time. The empirical material selected for this research consisted of 127 articles taken from the site escolasempartido.org. The investigation allowed us to verify the way Escola Sem Partido operates in the construction of discourse which points to a supposed hegemony of ideological indoctrination in schools, engaging in a dispute for truth in a process in which it rivaled even the academic literature itself.

KEYWORDS: Escola Sem Partido. Denouncement. Truth. Power. Science.

\section{CIENCIA, AUTORES Y VERDAD EN LOS DICTOS DEL MOVIMIENTO ESCOLA SEM PARTIDO: EL MECANISMO DE DENUNCIA}

RESUMEN: El movimiento Escola Sem Partido (Escuela sin partido) se hizo notable en los últimos años, en Brasil, por lanzar sucesivas investidas de poder sobre la categoría de 
enseñanza. Para tal proyecto fue necesario, entre otras acciones, fabricar un conjunto de conocimientos que le diera cierta legitimidad en el campo de la Educación. En este artículo, analizamos, a partir de la referencia teórica proveniente de Estudios Culturales e inspirados por el pensamiento de Michel Foucault, lo que llamamos como un mecanismo de denuncia: estrategia establecida para representar el movimiento como verdadero y necesario para nuestro tiempo. El material empírico seleccionado para esta investigación consistió en 127 artículos tomados del sitio escolasempartido.org. La investigación nos permitió verificar el modo en que opera la Escola Sem Partido en la construcción del discurso que apunta para una supuesta hegemonía del adoctrinamiento ideológico en las escuelas, envolviéndose en una disputa por la verdad en un proceso en el que incluso rivalizaba con la propia literatura académica educacional.

PALABRAS CLAVE: Escola Sem Partido. Denuncia. Verdad. Poder. Ciencia.

\section{Referências}

ALGEBAILE, E. Escola sem Partido: o que é, como age, para que serve. In: FRIGOTTO, G. (Org.). Escola "sem" Partido: esfinge que ameaça a educação e a sociedade brasileira. Rio de Janeiro: UERJ/LPP, 2017. p.63-74.

CARVAlHO, O. Currículo Vitae. (2017). Disponível em http://wpress.olavodecarvalho.org/wp-content/uploads/2017/06/Olavo-de-CarvalhoCurr\%C3\%ADculo.pdf >. Acessado em: 26 Nov. 2019

ESCOLA SEM PARTIDO. FAQ (IDE 004). 2016. Disponível em:〈http://escolasempartido.org/planeje-sua-denuncia〉. Acessado em: 14 Nov. 2016.

FAQ Programa Escola Sem Partido (IDE 006). 2016. Disponível em: <http://www.programaescolasempartido.org/FAQs>. Acessado em: 26 Jul. 2016.

FOUCAULT, M. Microfísica do poder. Rio de Janeiro: Edições Graal, v. 4, 1979.

. Vigiar e punir: nascimento da prisão. 38 ed. Petrópolis: Vozes, 2010.

. A ordem do discurso. São Paulo: ed. 24, Edições Loyola, 2014.

KATZ, E. P; MUTZ, A. S. C. Escola sem partido: uma análise das investidas de poder sobre as identidades docentes. Rev. Teoria e Prática da Educação, Maringá, v. 21,
n.2,
p.131-143,
2018.
Disponível
em: 
<http://periodicos.uem.br/ojs/index.php/TeorPratEduc/article/view/45393>. Acessado em: 28 Dez. 2018.

TRAVERSINI, C. S.; BELLO, S. E. L. O numerável, o mensurável e o auditável: estatística como tecnologia para governar. Educação \& Realidade, v. 34, n. 2, 2009.

Recebido em 11/02/2018.

Aprovado em 01/05/2019. 